\title{
The Unified Parkinson's Disease Rating Scale as a predictor of peak aerobic capacity and ambulatory function
}

\author{
Frederick M. Ivey, PhD; ${ }^{1-2 *}$ Leslie I. Katzel, MD, PhD; ${ }^{2-3}$ John D. Sorkin, MD, PhD; ${ }^{2-3}$ Richard F. Macko, MD; ${ }^{1-2}$ \\ Lisa M. Shulman, $\mathbf{M D}^{1}$ \\ ${ }^{1}$ University of Maryland School of Medicine, Department of Neurology, Baltimore, MD; ${ }^{2}$ Division of Gerontology and \\ Geriatric Medicine, Department of Veterans Affairs (VA) and VA Medical Center, Geriatric Research, Education and Clin- \\ ical Center, Baltimore, MD; ${ }^{3}$ University of Maryland School of Medicine, Department of Medicine, Baltimore, MD
}

\begin{abstract}
The Unified Parkinson's Disease Rating Scale (UPDRS) is a widely applied index of disease severity. Our objective was to assess the utility of UPDRS for predicting peak aerobic capacity $\left(\mathrm{VO}_{2}\right.$ peak) and ambulatory function. Participants $(n=70)$ underwent evaluation for UPDRS (Total and Motor ratings), $\mathrm{VO}_{2}$ peak, 6-minute walk distance (6MW), and 30-foot self-selected walking speed (SSWS). Using regression, we determined the extent to which the Total and Motor UPDRS scores predicted each functional capacity measure after adjusting for age and sex. We also tested whether adding the Hoehn and Yahr scale (H-Y) to the model changed predictive power of the UPDRS. Adjusted for age and sex, both the Total UPDRS and Motor UPDRS subscale failed to predict $\mathrm{VO}_{2}$ peak. The Total UPDRS did weakly predict $6 \mathrm{MW}$ and SSWS (both $p<0.05$ ), but the Motor UPDRS subscale did not predict these ambulatory function tests. After adding $\mathrm{H}-\mathrm{Y}$ to the model, Total UPDRS was no longer an independent predictor of $6 \mathrm{MW}$ but remained a predictor of SSWS. We conclude that Total and Motor UPDRS rating scales do not predict $\mathrm{VO}_{2}$ peak, but that a weak relationship exists between Total UPDRS and measures of ambulatory function.
\end{abstract}

Key words: 6-minute walk distance, ambulatory function, disease severity, endurance, motor function, Parkinson disease, self-selected walking speed, UPDRS, $\mathrm{VO}_{2}$ peak, walking.

\section{INTRODUCTION}

The Unified Parkinson's Disease Rating Scale (UPDRS) is the most widely applied rating instrument for Parkinson disease (PD) [1-2]. The Total UPDRS score includes 31 items contributing to three subscales: (I) Mentation, Behavior, and Mood; (II) Activities of Daily Living; and (III) Motor Examination [2]. The UPDRS does not assess general cardiovascular fitness and provides only limited information on functional performance relevant to daily activities, although this information would facilitate clinical decision-making. Therefore, there is value in determining the predictive power of the UPDRS for more time-consuming and resource-intensive measures such as peak aerobic capacity $\left(\mathrm{VO}_{2}\right.$ peak) and ambulatory function.

The UPDRS includes an examination of extrapyramidal motor function and has been shown to predict physical performance measures with a strong balance component, such as Berg Balance and the functional

Abbreviations: 6MW $=6$-minute walk distance, $\mathrm{H}-\mathrm{Y}=\mathrm{Hoehn}$ and Yahr scale, $\mathrm{PD}=$ Parkinson disease, $\mathrm{SE}=$ standard error, SSWS $=$ self-selected walking speed, UPDRS $=$ Unified Parkinson's Disease Rating Scale, VA = Department of Veterans Affairs, $\mathrm{VO}_{2}$ peak = peak aerobic capacity.

*Address all correspondence to Frederick M. Ivey, PhD; Department of Neurology, University of Maryland School of Medicine, Baltimore VA Medical Center Geriatrics Service/ GRECC, BT(18) GR, 10 North Greene St, Baltimore, MD 21201-1524; 410-637-3218; fax: 410-605-7913.

Email: fivey@grecc.umaryland.edu http://dx.doi.org/10.1682/JRRD.2011.06.0103 
reach tests [3-4]. Further, previous studies have shown that the UPDRS associates with daily function [3-5] and is sensitive to change over time [1] and across rehabilitation interventions [5-6]. However, uncertainty remains regarding the extent to which UPDRS predicts important aspects of function associated with ambulatory function, considering that prior investigations have failed to observe associations between UPDRS and 6-minute walk distance (6MW) [7] or between UPRDS and submaximal oxygen consumption during treadmill walking [8]. Importantly, no studies have evaluated whether the UPDRS predicts $\mathrm{VO}_{2}$ peak, a gold standard objective physical performance measure of cardiovascular fitness. Hence, the current study sought to enhance understanding about whether UPDRS predicts $\mathrm{VO}_{2}$ peak and ambulatory function by examining the relationship of Total and Motor UPDRS with $\mathrm{VO}_{2}$ peak, $6 \mathrm{MW}$, and floor walking speed. Based on limited prior work, we hypothesized that UPDRS would fall short of predicting $\mathrm{VO}_{2}$ peak and ambulatory function, both of which have an endurance requirement.

\section{METHODS}

\section{Subjects}

Recruits for this cross-sectional study came from the University of Maryland Parkinson's Disease Center and the Baltimore Department of Veterans Affairs (VA) Medical Center. All had volunteered to participate in a randomized exercise intervention trial designed specifically for PD patients. Entry criteria for this study have been described previously in Katzel et al. [9] and are included in the Appendix (available online only).

All tests of $\mathrm{VO}_{2}$ peak and ambulatory function were conducted on separate days to avoid the confounding effects of fatigue. The tests were done in the same order for all subjects. The treadmill $\mathrm{VO}_{2}$ peak test was done $1 \mathrm{wk}$ after assessment of ambulatory function (self-selected walking speed [SSWS] and 6MW). Further, all study evaluations (rating scales, $\mathrm{VO}_{2}$ peak, and ambulatory function testing) were conducted soon after medication intake $(<3 \mathrm{~h})$ while the subjects were "on." When required, subjects took an additional dose to maintain the "on" state during evaluation.

\section{Unified Parkinson's Disease Rating Scale Evaluation}

The UPDRS scale was scored by a single neurologist to avoid the confounding effects of interrater variability.
The evaluator is a board-certified neurologist and specialist in PD who is certified in the administration of the UPDRS. The UPDRS Total score was computed as the sum of UPDRS subscales I, II, and III.

\section{Peak Aerobic Capacity}

Treadmill testing was always conducted during the early afternoon hours when subjects were "on" soon after taking medication. Exercise tests were terminated according to American College of Sports Medicine guidelines [10]. Gait belts and other safety precautions protected against falls resulting from loss of balance. There were no falls during the treadmill $\mathrm{VO}_{2}$ peak tests or assessments of ambulatory function. Subjects were instructed to use as little handrail support as possible during the treadmill tests.

Both the treadmill testing ( $\mathrm{VO}_{2}$ peak) and overground ambulatory function testing (SSWS and 6MW) protocols have been previously described for this study population in articles by Katzel et al. [9,11], and those descriptions are provided in the Appendix (available online only).

\section{Statistical Methods}

Separate multiple regressions were used to evaluate UPDRS as a predictor of each of the three performance measures $\left(\mathrm{VO}_{2}\right.$ peak, SSWS, and 6MW). For each outcome, a separate analysis for both Total UPDRS and Motor UPDRS was run. All analyses were originally adjusted for age and sex. The models were then rerun after adding a simpler measure of disease progression (Hoehn and Yahr scale [H-Y]) to determine whether the predictive strength of the UPDRS remained. $\mathrm{H}-\mathrm{Y}$ is a clinical staging instrument that is even more widely utilized than UPDRS. Therefore, addition of H-Y to the model answers an important question related to whether UPDRS adds anything to the functional information obtained from the more routine H-Y scale. Probability values $\leq 0.05$ were considered significant.

\section{RESULTS}

\section{Subjects}

A total of 70 participants were studied. Fewer observations $(n=64)$ were available for the $6 \mathrm{MW}$ analysis because of missed tests. Participants were predominantly Caucasian (90\%) and male (71\%) and had a mean age of $65 \mathrm{yr}$ (Table 1). The mean H-Y score of 2.2 was indicative 
of a mild to moderately impaired population of PD participants. The means for SSWS, $6 \mathrm{MW}$, and $\mathrm{VO}_{2}$ peak were also consistent with mild to moderate disability. The diversity of disability is captured by the range of scores for the total UPDRS (15-89) and H-Y (1.5-3.0) (Table 1).

\section{Unified Parkinson's Disease Rating Scale as Predictor of Peak Aerobic Capacity}

Neither Total UPDRS $(-0.024 \pm 0.034, \beta \pm$ standard error [SE], $p=0.492)$ nor Motor UPDRS $(-0.038 \pm$ $0.048, \beta \pm \mathrm{SE}, p=0.429)$ were significant predictors of $\mathrm{VO}_{2}$ peak after correcting for age and sex (Table 2). Both age $(-0.190 \pm 0.042, p<0.001)$ and $\operatorname{sex}(-3.821 \pm 0.986$, $p<0.001)$ were independent predictors of $\mathrm{VO}_{2}$ peak. For each year of age, $\mathrm{VO}_{2}$ dropped by about $0.2 \mathrm{~mL} / \mathrm{kg} / \mathrm{min}$, and female participants with $\mathrm{PD}$ had $\mathrm{VO}_{2}$ peak measurements that were on average $3.8 \mathrm{~mL} / \mathrm{kg} / \mathrm{min}$ lower than males. Neither H-Y alone nor H-Y combined with the UPDRS measures was a significant predictor of $\mathrm{VO}_{2}$ peak.

\section{Unified Parkinson's Disease Scale as Predictor of Ambulatory Function}

When UPDRS ratings were evaluated for prediction of ambulatory function (6MW and SSWS), only Total

Table 1.

Participant characteristics.

\begin{tabular}{lcc}
\hline \multicolumn{1}{c}{ Variable } & Mean \pm SD & Range \\
\hline Age $(\mathrm{yr})(n=70)$ & $65 \pm 11$ & $42-86$ \\
Race (White: Black: Hispanic) & $63: 5: 2$ & - \\
Hoehn and Yahr Score & $2.2 \pm 0.4$ & $1.5-3.0$ \\
UPDRS Total Score & $47.1 \pm 12.8$ & $15-89$ \\
UPDRS Motor Score & $32.3 \pm 9.6$ & $11-59$ \\
Body Mass Index $\left(\mathrm{kg} / \mathrm{m}^{2}\right)$ & $28.4 \pm 5.0$ & $18.0-41.6$ \\
Self-Selected Walking Speed $(\mathrm{m} / \mathrm{s})$ & $1.1 \pm 0.2$ & $0.5-1.7$ \\
6-Minute Walk Distance $(\mathrm{m})(n=64)$ & $414 \pm 102$ & $122-654$ \\
VO ${ }_{2}$ Peak (mL/kg/min) & $21.4 \pm 4.2$ & $12.8-32.0$ \\
SD $=$ standard deviation, UPDRS = Unified Parkinson's Disease Rating Scale, $\mathrm{VO}_{2}$ peak = peak aerobic capacity. &
\end{tabular}

Table 2.

Relationship between Unified Parkinson's Disease Rating Scale (UPDRS) (Total and Motor scales) and peak aerobic capacity (VO 2 peak) with and without (bold) Hoehn-Yahr scale entered in model.

\begin{tabular}{|c|c|c|c|c|c|c|c|c|c|}
\hline \multirow{2}{*}{ Outcome } & \multirow{2}{*}{$N$} & \multirow{2}{*}{$R^{2}$} & \multirow{2}{*}{ Effect } & \multirow{2}{*}{ Intercept } & \multirow{2}{*}{ Age (yr) } & \multirow{2}{*}{ Sex (F vs $M)$} & \multirow{2}{*}{$\begin{array}{c}\text { Hoehn-Yahr } \\
\text { (Low vs High) }\end{array}$} & \multicolumn{2}{|c|}{ UPDRS } \\
\hline & & & & & & & & Total & Motor \\
\hline \multirow[t]{11}{*}{$\overline{\mathrm{VO}_{2} \text { peak }(\mathrm{mL} / \mathrm{kg} / \mathrm{min})}$} & 70 & 0.311 & $\beta$ & 35.995 & -0.190 & -3.821 & - & -0.024 & - \\
\hline & & & SE & 3.187 & 0.042 & 0.986 & - & 0.034 & 一 \\
\hline & & & $p$ & 0.000 & 0.000 & 0.000 & - & 0.492 & - \\
\hline & 70 & 0.313 & $\beta$ & 36.619 & -0.189 & -3.955 & -0.461 & -0.028 & - \\
\hline & & & $\mathrm{SE}$ & 3.583 & 0.042 & 1.050 & 1.179 & 0.036 & - \\
\hline & 70 & 0.313 & $\bar{\beta}$ & 36.015 & -0.187 & -3.966 & - & - & -0.038 \\
\hline & & & $\mathrm{SE}$ & 3.113 & 0.042 & 1.014 & - & - & 0.048 \\
\hline & & & $p$ & 0.000 & 0.000 & 0.000 & - & - & 0.429 \\
\hline & 70 & 0.314 & $\beta$ & 36.400 & -0.187 & -4.071 & -0.338 & - & -0.041 \\
\hline & & & $\mathrm{SE}$ & 3.389 & 0.042 & 1.080 & 1.131 & - & 0.049 \\
\hline & & & $p$ & 0.000 & 0.000 & 0.000 & 0.894 & - & - \\
\hline
\end{tabular}


UPDRS was an independent predictor for 6MW $(-2.122 \pm$ $0.884, \beta \pm \mathrm{SE}, p=0.020)$ and SSWS $(-0.005 \pm 0.002, p=$ 0.008 ) after adjusting for age and sex (Table 3). Total UPDRS, age, and sex explained 16 percent of the variance in $6 \mathrm{MW}$ and 24 percent of the variance in SSWS, indicating a weak but statistically significant relationship (Figure). Conversely, Motor UPDRS was not a significant predictor of either SSWS or 6MW, adjusting for age and sex. For both ambulatory function tests, age but not sex was a significant independent predictor. When $\mathrm{H}-\mathrm{Y}$ score was added to the model, the Total UPDRS was no longer a significant independent predictor of $6 \mathrm{MW}$, but the independent relationship between Total UPDRS and SSWS was retained ( $p=0.046$ ) (Table 3). Thus, the independent predictive strength of Total UPDRS for longer distance ambulatory function was compromised when a simpler global measure of disease severity was added. $\mathrm{H}-\mathrm{Y}$ evaluated alone without UPDRS in the model did predict a significant portion of the variance for both ambulatory function measures (Table 3).

Table 3.

Relationship between Unified Parkinson's Disease Rating Scale (UPDRS) and function accessed by 6-Minute Walk Distance and Self-Selected Walking Speed with and without (bold) Hoehn-Yahr entered in model.

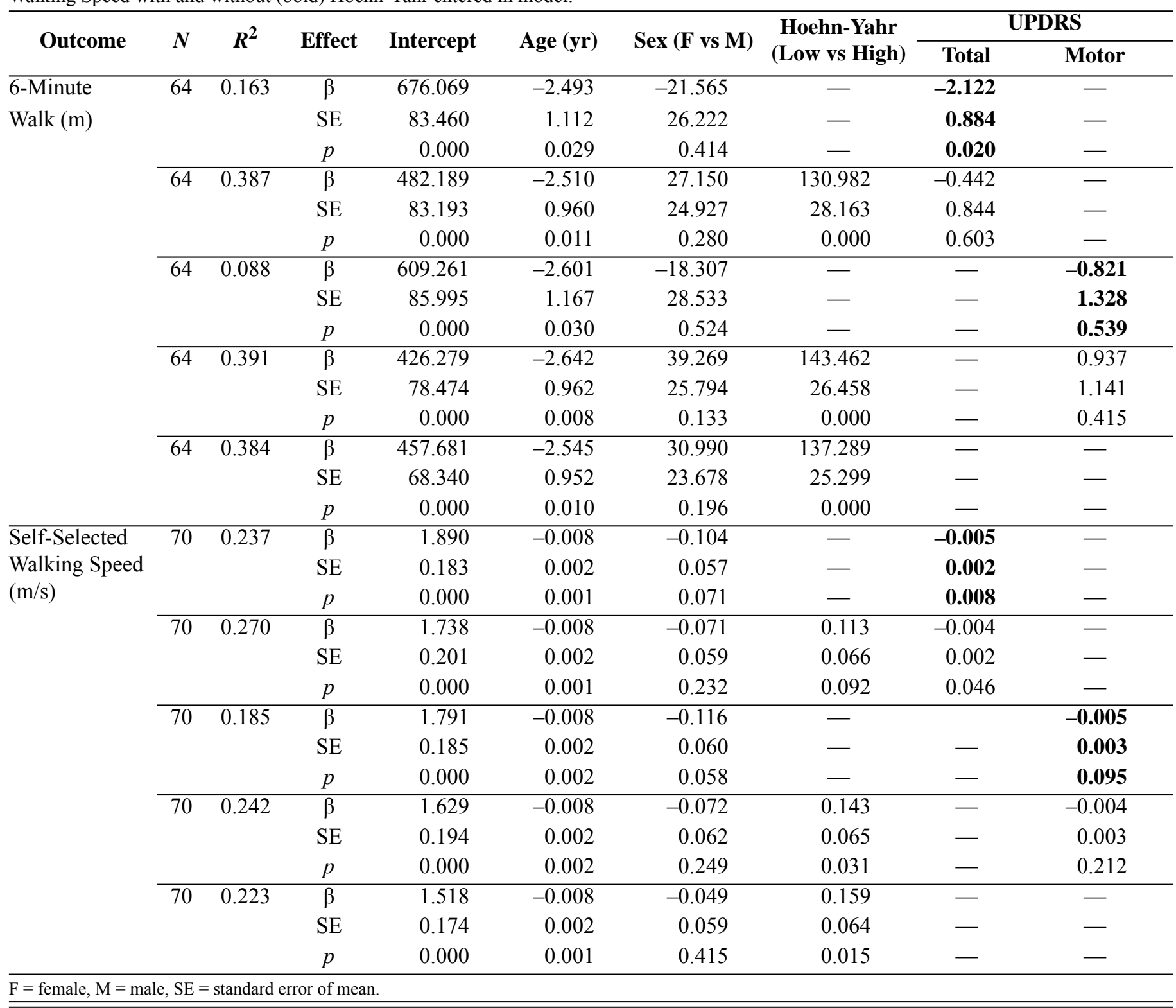




\section{DISCUSSION}

Our results show that neither the Total nor Motor UPDRS predicts $\mathrm{VO}_{2}$ peak in mild to moderate PD. Total UPDRS but not Motor UPDRS was found to weakly predict ambulatory function. These findings extend the work of previous investigations on the clinical and functional significance of UPDRS ratings [3,12-13].

The UPDRS is the most common instrument used to track PD severity and is widely considered the gold standard for evaluation of PD in both clinical and research settings [1-2]. The UPDRS has attained this status based on both its reliability [14-16] and sensitivity to change over time [6,17]. Nonetheless, the relationship between UPDRS ratings and progression of disability is not fully understood [18-19]. The ability of the UPDRS to predict performance on quantitative tests of physical function has also not been fully established [3]. Our study shows that UPDRS is not associated with $\mathrm{VO}_{2}$ peak, a performance measure relevant to cardiovascular and metabolic health as well as general functional capacity. Items in the UPDRS focus predominantly on the motor features of PD including bradykinesia, rigidity, and tremor [1-2]. Nonmotor features of PD such as cognitive impairment, autonomic dysfunction, depression, and sleep disorders have received increasing attention in recent years [20-21] and may contribute to variations in functional status. Interestingly, none of the items on the UPDRS assess the level of physical activity or endurance.

The UPDRS has been shown to predict physical performance measures with a strong balance component. For example, Tanji et al. compared ratings on the Berg Balance Scale and Functional Reach tests with Total and Motor UPDRS in 79 participants with a range of PD severity [3]. The results showed relatively strong correlations between UPDRS ratings and these measures of physical performance. Similarly, Brusse et al. found associations between the UPDRS and tests of balance, but failed to observe associations with ambulatory function [4]. They concluded that the single item of gait assessment in the Motor UPDRS (item 29) is inadequate to reflect walking performance [4]. This point may also be relevant to the weak performance of the UPDRS in predicting the ambulatory function and $\mathrm{VO}_{2}$ peak measures in this study. Hence, previous studies indicate that the UPDRS may be a decent predictor of short physical performance measures with a strong balance component, but our results and others cast doubt on its utility for predicting


Figure.

Scatter plots depicting relationship between total Unified Parkinson's Disease Rating Scale (UPDRS) and (a) 6-minute walk or (b) self-selected walking speed (SSWS). Modest but significant relationship disappeared after adding Hoehn and Yahr to model for (a) but not (b).

ambulatory function and $\mathrm{VO}_{2}$ peak performance, which requires sustained effort and a degree of endurance. Although studies have shown that the UPDRS is correlated with community ambulation patterns as measured by step activity monitoring [5], the distance walked over the course of a day in the community is a different aspect of function than measures of ambulatory function and $\mathrm{VO}_{2}$ peak obtained during formal laboratory testing. This is based on the higher levels of effort required for the laboratory tests. Both our findings and those of Falvo and Earhart [7] 
demonstrate that the UPDRS is not an independent predictor of $6 \mathrm{MW}$ when age and $\mathrm{H}-\mathrm{Y}$ are added to the regression model.

The absence of an association between UPDRS and $\mathrm{VO}_{2}$ peak observed in this study is partially supported by previous studies measuring $\mathrm{VO}_{2}$ in $\mathrm{PD}$. Canning et al. showed that $\mathrm{VO}_{2}$ peak during cycle ergometry was not related to disease severity as assessed by $\mathrm{H}-\mathrm{Y}$ staging [22]. Additionally, Christiansen et al. measured submaximal $\mathrm{VO}_{2}$ during treadmill walking in $\mathrm{PD}(2.3 \mathrm{mph}, 0$ grade) and found that $\mathrm{VO}_{2}$ was not correlated with Total UPDRS [8]. In combination with our results, it is reasonable to conclude that, in patients with mild to moderate PD, the UPDRS does not reflect either peak or submaximal aerobic performance.

Limitations of this study include the failure to study the full range of PD severity. Because we studied subjects with mild to moderate impairment (H-Y 1.5-3 while "on," mean $2.2 \pm 0.4$ ), our results may not be generalizable to the full spectrum of disease severity. Floor effects may limit sensitivity of the UPDRS in milder stages of the disease [1]. In addition to studying a broader range of disease severity, future studies should compare UPDRS with a larger battery of objective functional outcome tests. In this study, the majority of patients $(57 \%)$ did not experience motor fluctuations, while 43 percent had fluctuations. There is no way to completely eliminate potential effects from varying medication levels. However, we attempted to proactively address this by performing exercise and study evaluations while the subjects were within $3 \mathrm{~h}$ of antiparkinsonian medication administration. If participants perceived that their medications were wearing off, our protocol permitted administration of an additional dose of antiparkinsonian medication, but this was not necessary during the study.

\section{CONCLUSIONS}

To summarize, the results shed additional light on the functional and clinical relevance of the UPDRS. The data show that PD severity assessed by the UPDRS Motor Examination subscale does not predict $\mathrm{VO}_{2}$ peak or ambulatory function (6MW, SSWS). Further, Total UPDRS does not predict $\mathrm{VO}_{2}$ peak but does independently predict SSWS, albeit modestly. Although there was a weak association between 6MW and Total UPDRS, the relationship disappeared after adding $\mathrm{H}-\mathrm{Y}$ to the model. Lack of association with $\mathrm{VO}_{2}$ peak may partly be a function of the underemphasis of UPDRS items on ambulatory function and associated elements of endurance. The UPDRS will continue to be widely used in assessing disease progression and the effectiveness of neuroprotective agents and for therapeutic decision-making by clinicians $[2,13]$. Hence, increased understanding about the scale's limitations in predicting results on ambulatory function and $\mathrm{VO}_{2}$ peak tests is important. Future attempts at revising the UPDRS scale should consider components related to sustained activity and endurance.

\section{ACKNOWLEDGMENTS}

\section{Author Contributions:}

Study concept and design: L. M. Shulman, R. F. Macko. Acquisition of data: F. M. Ivey, L. I. Katzel.

Analysis and interpretation of data: F. M. Ivey, L. I. Katzel, J. D. Sorkin. Drafting of manuscript: F. M. Ivey.

Critical revision of manuscript for important intellectual content: F. M. Ivey, L. I. Katzel, J. D. Sorkin, R. F. Macko, L. M. Shulman. Statistical analysis: J. D. Sorkin. Obtained funding: L. M. Shulman.

Administrative, technical, or material support: L. M. Shulman, F. M. Ivey, L. I. Katzel.

Study supervision: F. M. Ivey, L. I. Katzel, L. M. Shulman.

Financial Disclosures: The authors have declared that no competing interests exist.

Funding/Support: This material was based on work supported by a grant from the Michael J. Fox Foundation for Parkinson's Research (Shulman). Additional resources were provided by the VA Medical Center Baltimore Geriatric Research, Education and Clinical Center, The National Institute on Aging Claude D. Pepper Older Americans Independence Center (P30-AG028747), and the VA Rehabilitation Research and Development Exercise \& Robotics Center of Excellence (Macko).

Institutional Review: The Institutional Review Board at the University of Maryland, Baltimore, approved this study, and all participants provided written consent.

Participant Follow-Up: The authors do not plan to inform participants of the publication of this study.

\section{REFERENCES}

1. Ebersbach G, Baas H, Csoti I, Müngersdorf M, Deuschl G. Scales in Parkinson's disease. J Neurol. 2006;253(Suppl 4): IV32-35. [PMID:16944355] http://dx.doi.org/10.1007/s00415-006-4008-0

2. Poewe W. Clinical measures of progression in Parkinson's disease. Mov Disord. 2009;24(S2):S671-76.

3. Tanji H, Gruber-Baldini AL, Anderson KE, Pretzer-Aboff I, Reich SG, Fishman PS, Weiner WJ, Shulman LM. A comparative study of physical performance measures in Parkinson's 
disease. Mov Disord. 2008;23(13):1897-1905.

[PMID:18709681]

http://dx.doi.org/10.1002/mds.22266

4. Brusse KJ, Zimdars S, Zalewski KR, Steffen TM. Testing functional performance in people with Parkinson disease. Phys Ther. 2005;85(2):134-41. [PMID:15679464]

5. Skidmore FM, Mackman CA, Pav B, Shulman LM, Garvan C, Macko RF, Heilman KM. Daily ambulatory activity levels in idiopathic Parkinson disease. J Rehabil Res Dev. 2008; 45(9):1343-48. [PMID:19319758] http://dx.doi.org/10.1682/JRRD.2008.01.0002

6. Schrag A, Spottke A, Quinn NP, Dodel R. Comparative responsiveness of Parkinson's disease scales to change over time. Mov Disord. 2009;24(6):813-18. [PMID:19199355] http://dx.doi.org/10.1002/mds.22438

7. Falvo MJ, Earhart GM. Six-minute walk distance in persons with Parkinson disease: a hierarchical regression model. Arch Phys Med Rehabil. 2009;90(6):1004-8.

[PMID:19480877]

http://dx.doi.org/10.1016/j.apmr.2008.12.018

8. Christiansen CL, Schenkman ML, McFann K, Wolfe P, Kohrt WM. Walking economy in people with Parkinson's disease. Mov Disord. 2009;24(10):1481-87. [PMID:19441128] http://dx.doi.org/10.1002/mds.22621

9. Katzel LI, Ivey FM, Sorkin JD, Macko RF, Smith B, Shulman LM. Impaired economy of gait and decreased six-minute walk distance in Parkinson's disease. Parkinsons Dis. 2012; 2012:1-6.

10. American College of Sports Medicine. Guidelines for exercise testing and prescription. Baltimore (MD): Lippincott, Williams \& Wilkins; 2006.

11. Katzel LI, Sorkin JD, Macko RF, Smith B, Ivey FM, Shulman LM. Repeatability of aerobic capacity measurements in Parkinson disease. Med Sci Sports Exerc. 2011;43(12): 2381-87. [PMID:21606869] http://dx.doi.org/10.1249/MSS.0b013e31822432d4

12. Schrag A, Sampaio C, Counsell N, Poewe W. Minimal clinically important change on the unified Parkinson's disease rating scale. Mov Disord. 2006;21(8):1200-7. [PMID:16673410] http://dx.doi.org/10.1002/mds.20914

13. Shulman LM, Gruber-Baldini AL, Anderson KE, Fishman PS, Reich SG, Weiner WJ. The clinically important difference on the unified Parkinson's disease rating scale. Arch Neurol. 2010;67(1):64-70. [PMID:20065131] http://dx.doi.org/10.1001/archneurol.2009.295

14. Metman LV, Myre B, Verwey N, Hassin-Baer S, Arzbaecher J, Sierens D, Bakay R. Test-retest reliability of UPDRS-III, dyskinesia scales, and timed motor tests in patients with advanced Parkinson's disease: an argument against multiple baseline assessments. Mov Disord. 2004;19(9):1079-84. [PMID:15372601]

http://dx.doi.org/10.1002/mds.20101
15. Martinez-Martin P, Forjaz MJ. Metric attributes of the unified Parkinson's disease rating scale 3.0 battery: Part I, feasibility, scaling assumptions, reliability, and precision. Mov Disord. 2006;21(8):1182-88. [PMID:16673397]

http://dx.doi.org/10.1002/mds.20916

16. Martínez-Martín P, Gil-Nagel A, Gracia LM, Gómez JB, Martínez-Sarriés J, Bermejo F; The Cooperative Multicentric Group. Unified Parkinson's Disease Rating Scale characteristics and structure. Mov Disord. 1994;9(1):76-83. [PMID:8139608]

http://dx.doi.org/10.1002/mds.870090112

17. Frazzitta G, Maestri R, Bertotti G, Uccellini D, Bazzini G, Abelli P, Aquilani R. Rehabilitation in Parkinson's disease: assessing the outcome using objective metabolic measurements. Mov Disord. 2010;25(5):609-14.

[PMID:20201004]

http://dx.doi.org/10.1002/mds.22871

18. Shulman LM, Gruber-Baldini AL, Anderson KE, Vaughan CG, Reich SG, Fishman PS, Weiner WJ. The evolution of disability in Parkinson disease. Mov Disord. 2008;23(6): 790-96. [PMID:18361474] http://dx.doi.org/10.1002/mds.21879

19. Espay AJ, Beaton DE, Morgante F, Gunraj CA, Lang AE, Chen R. Impairments of speed and amplitude of movement in Parkinson's disease: a pilot study. Mov Disord. 2009; 24(7):1001-8. [PMID:19230031]

http://dx.doi.org/10.1002/mds.22480

20. Poewe W. The natural history of Parkinson's disease. J Neurol. 2006;253(Suppl 7):VII2-6. [PMID:17131223]

http://dx.doi.org/10.1007/s00415-006-7002-7

21. Post B, Merkus MP, de Haan RJ, Speelman JD. Prognostic factors for the progression of Parkinson's disease: a systematic review. Mov Disord. 2007;22(13):1839-51.

22. Canning CG, Alison JA, Allen NE, Groeller H. Parkinson's disease: an investigation of exercise capacity, respiratory function, and gait. Arch Phys Med Rehabil. 1997;78(2): 199-207. [PMID:9041903] http://dx.doi.org/10.1016/S0003-9993(97)90264-1

Submitted for publication June 8, 2011. Accepted in revised form January 6, 2012.

This article and any supplementary material should be cited as follows:

Ivey FM, Katzel LI, Sorkin JD, Macko RF, Shulman LM. The Unified Parkinson's Disease Rating Scale as a predictor of peak aerobic capacity and ambulatory function. J Rehabil Res Dev. 2012;49(8):1269-76. http://dx.doi.org/10.1682/JRRD.2011.06.0103

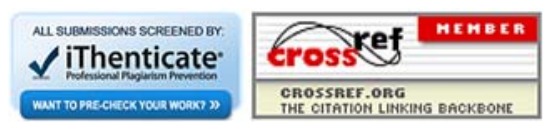


